\title{
Assay for Evaluating the Abundance of Vibrio Cholerae and Its O1 Serogroup Subpopulation Directly from Water Without DNA Extraction
}

\author{
Tania Nasreen a, Nora A.S. Hussain a , Jia Yee Ho b, c, Vanessa Zhi Jie Aw b, c, Munirul Alam d, Stephanie K. Yanow e, \\ f, Yann F. Boucher ${ }^{b, c *}$ \\ a Department of Biological Sciences, University of Alberta, Edmonton, Alberta T6G 2E9, Canada \\ (tnasreen@ualberta.ca, nahussai@ualberta.ca) \\ b Singapore Centre for Environmental Life Sciences Engineering (SCELSE), National University of Singapore, \\ Singapore 637551, Singapore \\ c Saw Swee Hock School of Public Health and National University Hospital System, National University of \\ Singapore, Singapore 117549, Singapore (J.Y.H.: jiayeeho@nus.edu.sg, V.Z.J.A.: vanessa.azj@nus.edu.sg) \\ d Centre for Communicable Diseases, International Centre for Diarrhoeal Disease Research, Bangladesh \\ (ICDDR, B), Dhaka, Bangladesh (munirul@icddrb.org) \\ e School of Public Health, University of Alberta, Edmonton, Alberta T6G 2E9, Canada (yanow@ualberta.ca) \\ f Department of Medical Microbiology and Immunology, University of Alberta, Edmonton, Alberta T6G 2E9, \\ Canada \\ * Correspondence: ephyb@nus.edu.sg
}

\begin{abstract}
Cholera is a severe diarrheal disease caused by Vibrio cholerae, a natural inhabitant of brackish water. Effective control of cholera outbreaks depends on prompt detection of the pathogen from clinical specimens and tracking its source in the environment. Although the epidemiology of cholera is well studied, rapid detection of $V$. cholerae remains a challenge, and data on its abundance in environmental sources are limited. Here, we describe a sensitive molecular quantification assay by qPCR, which can be used on-site in low resource settings directly on water without the need for DNA extraction. This newly optimized method exhibited $100 \%$ specificity for total $V$. cholerae as well as $V$. cholerae $\mathrm{O} 1$ and allowed detection of as few as three target genome copies per reaction. The limit of detection is as low as $5 \times 10^{3}$ genome copies/L of water after concentrating biomass from the sample. The ability to perform qPCR directly on water samples, portable features of the equipment, stability of the reagents at $4^{\circ} \mathrm{C}$ and user-friendly online software facilitate fast quantitative analysis of $V$. cholerae. These characteristics make this assay extremely useful for field research in resourcepoor settings and could support continuous monitoring in cholera endemic areas.
\end{abstract}

Keywords: cholera; Vibrio cholerae; Vibrio cholerae O1; endemic; toxigenic; abundance and qPCR

\section{Introduction}

Cholera is a life-threatening diarrheal disease caused by pathogenic strains of Vibrio cholerae. Today, cholera still persevere as a global threat to public health due to its high morbidity and mortality rates [1-5]. There were around 250,000 suspected cholera cases and over 3,500 deaths reported in 2021 [6] and an estimated 2.9 million cases and 95,000 deaths occur each year around the world [7]. Lack of access to safe drinking water and inadequate management of sanitary systems in resource-poor countries are two major reasons this disease remains a significant public health problem. Current data on the global disease burden of cholera identify 47 countries around the world affected by cholera, and over half a billion people reside in areas that are labelled as cholera hotspots [8]. Cholera outbreaks in recent years affecting Haiti, Somalia, Ethiopia, Iraq, Mozambique, Zambia, Sudan, Nepal and Zimbabwe demonstrated that devastation, from an earthquake, for example, can cause an outbreak [9]. In 2018, the epidemic in Yemen was reported to be the world's fastest-growing outbreak, where 10,000 suspected cases were 
reported on a weekly basis [10]. The cumulative impact of cholera in Yemen currently sits at a death toll of nearly four thousand since October 2016, with over 2.5 million people infected so far [11].

$V$. cholerae is naturally found worldwide, especially in brackish riverine, coastal and estuarine environments [12]. Not all $V$. cholerae present in nature are pathogenic, and only a subset of strains is known threat to humans. Amongst the 200 serogroups of this species, only $\mathrm{O} 1$ and $\mathrm{O} 139$ are associated with cholera cases (toxigenic serogroups) and are responsible for epidemic and pandemic cholera outbreaks [13-15].

Estimation of $V$. cholerae abundance, along with that of its pandemic generating serogroups [16] in aquatic ecosystems is difficult, because of the high spatio-temporal variability exhibited by its natural populations [17]. Epidemiological studies and analysis of cholera outbreaks revealed that the disease occurs in a regular seasonal pattern in cholera-endemic areas [18-20] and causes outbreaks only under certain conditions, which may be attributed to environmental and climatic factors, for example, heavy rainfall followed by blooms of phytoplankton and zooplankton [21-24].

Although cholera has been endemic to the Ganges Delta for centuries, it is an imported disease in most other locales, where it can vanish after a single outbreak or linger for decades before disappearing. For example, Haiti had no recorded cholera for centuries [25-28], but the disease rapidly spread after the 2010 earthquake which devastated infrastructure in the country and with the arrival of United Nations' (UN) troops carrying the bacteria from Nepal [28,29]. The country then faced a decade of the cholera epidemic before the disease faded in 2019 - 2020 [30]. Because of these epidemiological dynamics, cholera has been categorized as an emerging and re-emerging infectious disease [31,32].

In addition, surveillance of cholera outbreaks through clinical diagnosis provides an estimation of the associated disease burden but it is unable to provide quantitative information of the pathogen or its abundance in source environments. To achieve a better understanding of the cholera prevalence and to direct appropriate control measures and treatment, it is necessary to identify and promptly quantify its causative agent in its reservoir. However, one of the major obstacles is that the number of $V$. cholerae (toxigenic and non-toxigenic) is often below the limit of detection of current field analytical methods, even during outbreaks [33].

Conventional culture methods remains the gold standard for laboratory diagnosis of cholera [34,35] and often requires pre-enrichment of the sample [36]. Moreover, two to three days are required to conduct testing even with modern laboratory infrastructure. With these methods, isolation and identification are possible, but the total abundance quantified is often underestimated, as a considerable proportion of most populations exists as viable but non-culturable cells (VBNC), which do not revive upon culturing on microbiological media [36,37]. In areas with limited or no laboratory facilities, simple dark-field microscopy is used to detect characteristic movement of $V$. cholerae in stool samples but this method is not feasible on water sources where the bacterium is much more dilute [38]. The Crystal ${ }^{\circledR}$ VC Rapid Diagnostic Test (RDT) is also used for point-of-care detection to predict potential cholera outbreaks where this diagnostic test uses stool sample and is mainly based on detection of either cholera toxin $[39,40]$ or a lipopolysaccharide antigen $[39,41,42]$. It is useful to detect serogroups $\mathrm{O} 1$ and $\mathrm{O} 139$. However, due to the poor sensitivity and specificity of this method, additional tests are required to confirm the presence of toxigenic $V$. cholerae in stool sample [39]. A Direct Fluorescent Antibody (DFA) technique using polyclonal anti-O1 serum is also used to detect $V$. cholerae $\mathrm{O} 1$ in smears prepared from samples. This procedure has been used for both clinical and pre-enriched environmental samples [36,43]. Despite these methods facilitating cholera diagnosis, most of them are qualitative, only detect $V$. cholerae $\mathrm{O} 1$ or $\mathrm{O} 139$ serogroup and have been optimized for clinical but not environmental specimens.

To improve cholera surveillance, it is essential to accurately determine the abundance of the total and disease-causing serogroups of $V$. cholerae in its reservoir. To achieve this goal, we designed two species-specific primers and probes to precisely detect and quantify total $V$. cholerae and $V$. cholerae $\mathrm{O} 1$ serotype directly from environmental water samples 
without DNA extraction. Employing the Chai Open qPCR equipment - a low cost, portable qPCR machine - we demonstrate the potential for our designed set of qPCR primers to be utilized during field sampling. In-field quantification of prokaryotic and eukaryotic constituents of interest using Open qPCR have been recently performed on recreational waters in Alberta and present comparable results to conventional qPCR equipment [44]. Altogether, this method can determine the absolute abundance of this bacterium and the main serogroup associated with pathogenicity across hundreds of samples in a spatiotemporal gradient, making it possible to pinpoint the source of cholera outbreaks and warn of potential outbreaks.

\section{Results}

\subsection{Analytical validation}

The qPCR assay was validated by using a blind panel of filter-sterilized environmental water samples collected from the Gabtoli area (Dhaka, Bangladesh) (FIGURE 1) and spiked with $V$. cholerae reference strains.

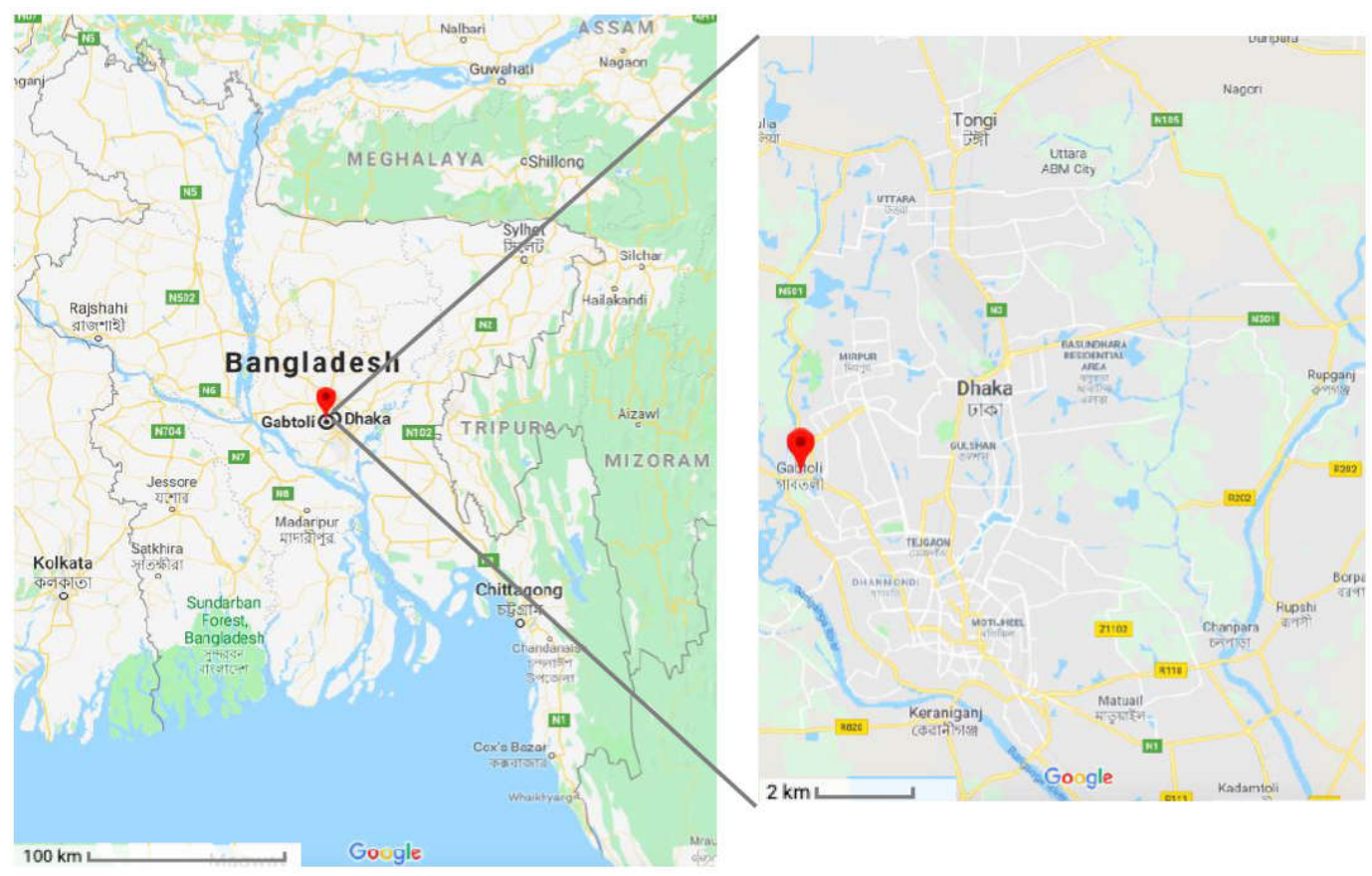

Figure 1. Environmental water sampling sites in Bangladesh. An endemic site for V. cholerae is shown on the map of Bangladesh. Environmental water samples were collected from the river basin of Turag river in Gabtoli area in Dhaka city, an inland region of Bangladesh. Samples were collected in triplicate from three locations that were 5 metres apart (Image source: Google).

Forty-six bacterial isolates of known concentration of $3 \times 10^{4} \mathrm{CFU} / \mathrm{mL}$ (CFU - colony forming unit) were tested, including non-O1 $V$. cholerae, $V$. cholerae $\mathrm{O} 1$, other Vibrio species (V. parahaemolyticus, V. vulnificus, V. metoecus, V. mimicus), as well as non-Vibrio species (Escherichia coli and Pseudomonas aeruginosa) (TABLE 1). All seventeen non-O1 V. cholerae and eight $V$. cholerae $\mathrm{O} 1$ were positive for $v i u B$ gene. Only samples spiked with $V$. cholerae $\mathrm{O} 1$ strains were positive for the $\mathrm{rfbO1}$ gene. The other Vibrio spp. and non-Vibrio species were negative for these two gene targets. Thus, the analytical specificity (i.e. the ability of an assay to detect and/or measure a specific organism in a sample) of this method was $100 \%$ (TABLE 1). Analytical sensitivity was also found to be $100 \%$ based on detection of 3 CFU/reaction (TABLE 2).

Table 1. Bacterial strains used in the analytical validation of this assay 


\begin{tabular}{|c|c|c|c|c|c|c|}
\hline Species & $\begin{array}{l}\text { No. of } \\
\text { strains }\end{array}$ & Strain & Targ & enes & Source & Reference \\
\hline & & & $\operatorname{viu} B$ & $r f b O 1$ & & \\
\hline \multicolumn{7}{|l|}{ V. cholerae } \\
\hline \multirow[t]{17}{*}{$V$. cholerae non $\mathrm{O} 1$} & 17 & OYP1G01 & + & - & Environmental & This study \\
\hline & & OYP2A12 & + & - & Environmental & This study \\
\hline & & OYP2E01 & + & - & Environmental & This Study \\
\hline & & OYP3B05 & + & - & Environmental & {$[45]$} \\
\hline & & OYP3F10 & + & - & Environmental & This study \\
\hline & & OYP4B01 & + & - & Environmental & This study \\
\hline & & OYP4C07 & + & - & Environmental & {$[45]$} \\
\hline & & OYP4G08 & + & - & Environmental & This study \\
\hline & & OYP4H06 & + & - & Environmental & This study \\
\hline & & OYP4H11 & + & - & Environmental & This study \\
\hline & & OYP6D06 & + & - & Environmental & This study \\
\hline & & OYP6E07 & + & - & Environmental & This study \\
\hline & & OYP6F08 & + & - & Environmental & This study \\
\hline & & OYP6F10 & + & - & Environmental & This study \\
\hline & & OYP7C09 & + & - & Environmental & This study \\
\hline & & OYP8C06 & + & - & Environmental & This study \\
\hline & & OYP8F12 & + & - & Environmental & This study \\
\hline \multirow[t]{8}{*}{ V. cholerae $\mathrm{O} 1$} & 8 & N16961 & + & + & Clinical & {$[46]$} \\
\hline & & V52 & + & + & Clinical & [47] \\
\hline & & EDC-728 & + & + & Environmental & This study \\
\hline & & EDC-753 & + & + & Environmental & This study \\
\hline & & EDC-754 & + & + & Environmental & This study \\
\hline & & EDC-755 & + & + & Environmental & This study \\
\hline & & EDC-772 & + & + & Environmental & This study \\
\hline & & EDC-805 & + & + & Environmental & This study \\
\hline \multicolumn{7}{|l|}{ Other Vibrio species } \\
\hline V. parahaemolyticus & 1 & ATCC 17802 & - & - & Clinical & [48] \\
\hline
\end{tabular}

Other Vibrio species

Clinical

Clinical

ATCC 27562

- Clinical

[48]

V. vulnificus

3

MO6-24

CECT 5769

-
-
-

-

Environmental

V. metoecus

10

RC341
OP3H
OYP4D01
OYP4E03
OYP5B04
OYP5B06
OYP5H08

$\begin{array}{ll}- & - \\ - & - \\ - & - \\ - & - \\ - & -\end{array}$

Environmental

This study

This study 


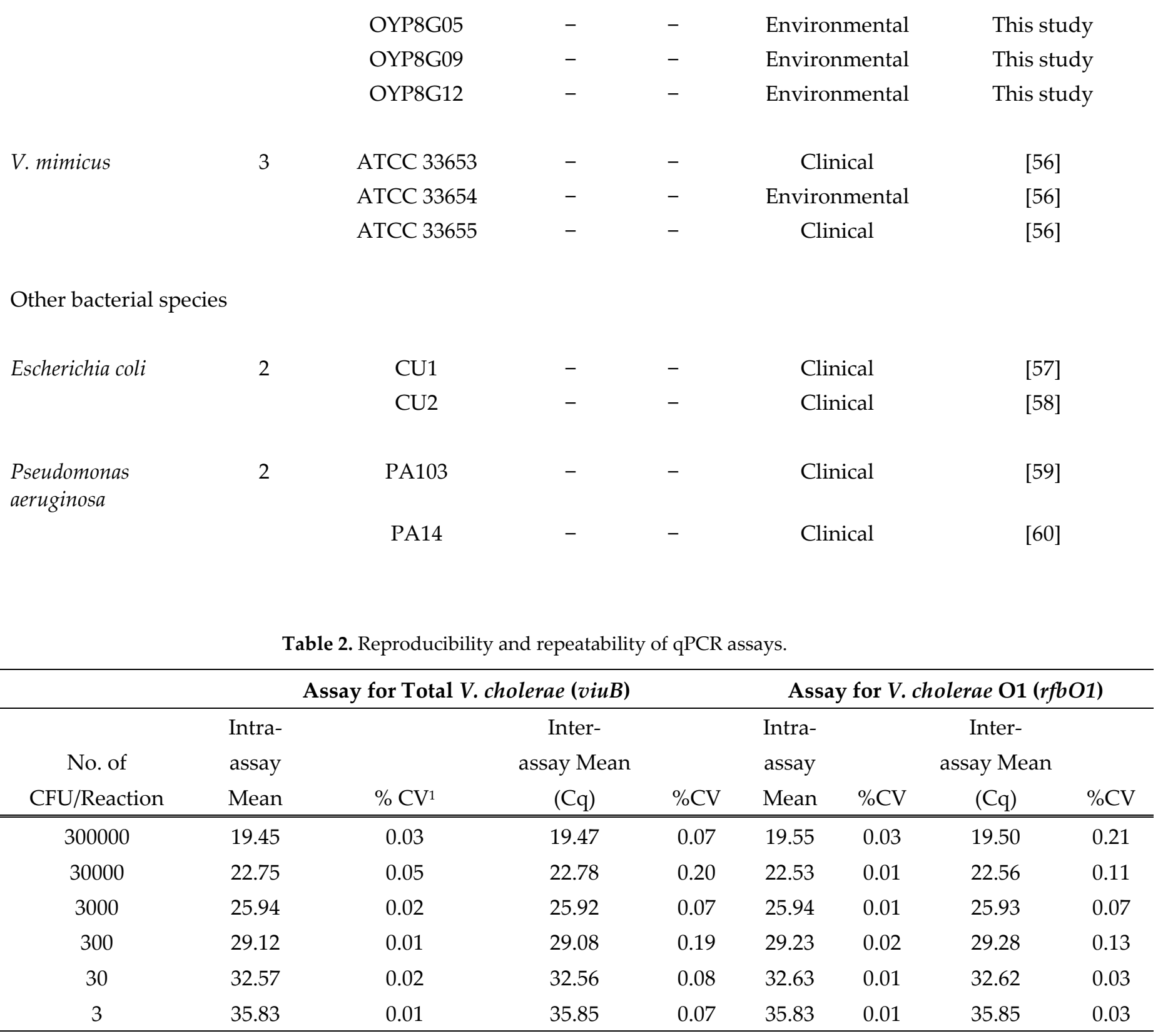

$1 \% \mathrm{CV}$ : percent coefficient of variation

\subsection{Limit of Detection (LOD)}

The LOD of the assay was determined as 3 copies per reaction from the standard curve constructed using serially diluted standards of the V. cholerae El Tor O1 N16961 reference strain (FIGURE 2). We also determined a Sample Limit of Detection (SLOD) of $5 \times$ $10^{3} \mathrm{CFU} / \mathrm{L}$ for the filter-sterilized environmental water samples $(5 \mathrm{~mL})$ spiked with a known number of $V$. cholerae N16961 concentrated to $\sim 10 \mu \mathrm{L}$ with an Amicon ultra-0.5 centrifugal filter device (TABLE S1). 
A.

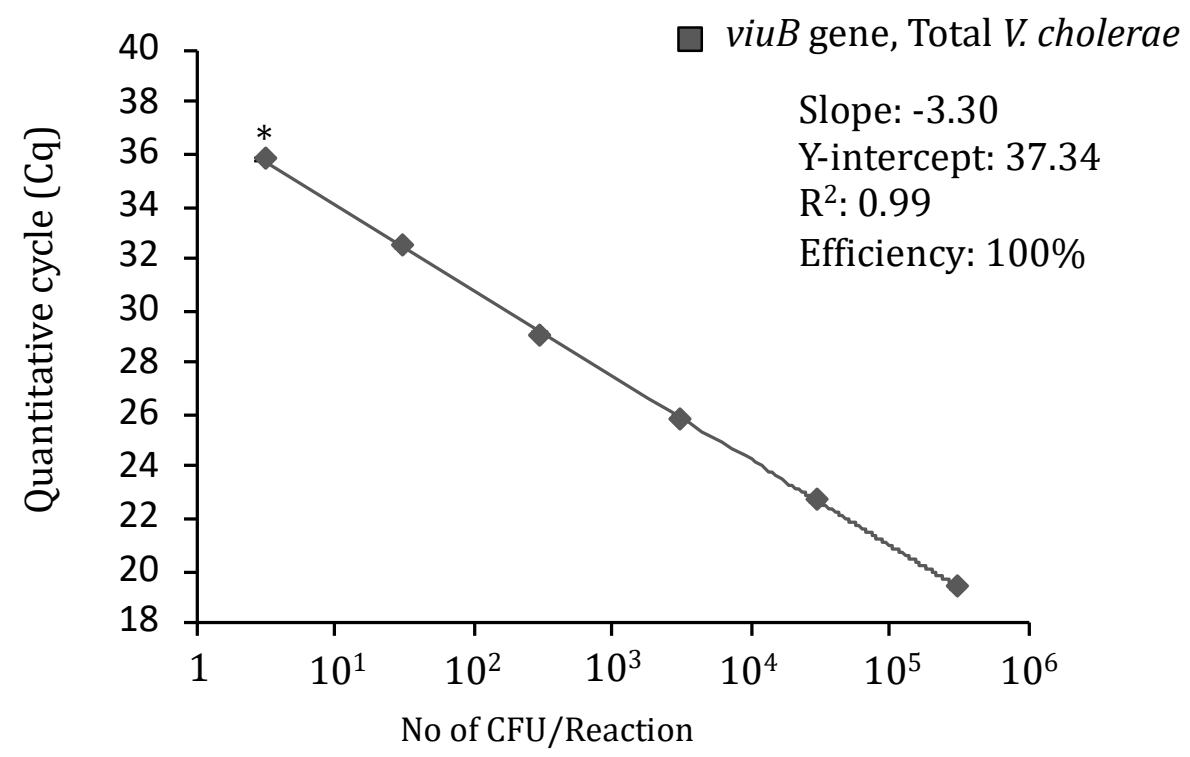

B.

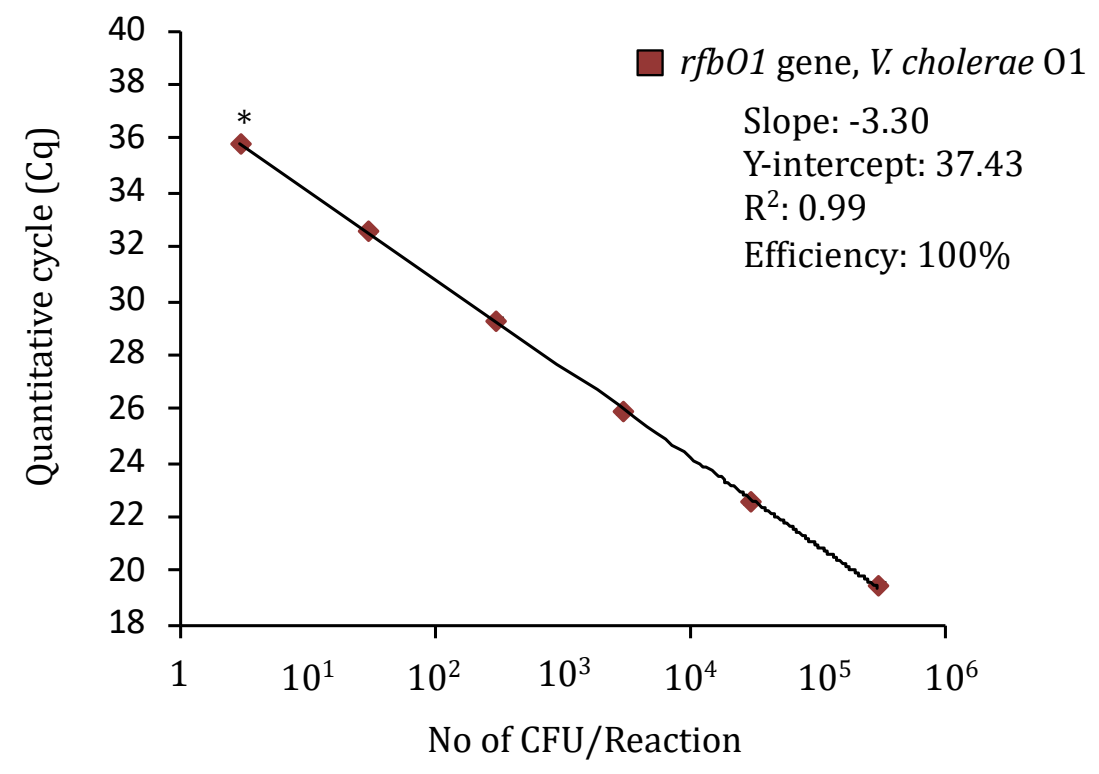

Figure 2. Standard curves for detection and quantification of total V. cholerae and V. cholerae O1 by qPCR. Two gene markers with fluorogenic probes, A) viuB (V. cholerae specific) and B) $r f b O 1$ ( $V$. cholerae O1 specific) were used. Cells of reference culture (V. cholerae N16961 El Tor O1) were serially diluted 10-fold to yield concentrations ranging 3 to $3 \times 10^{6}$ copies per reaction (from left to right.) Fluorescence was measured in relative units.

\subsection{Assay precision and efficiency}

Following the Minimum Information for Publication of Quantitative qPCR Experiments (MIQE) guidelines, intra-assay variation (variation between replicates in the same experiment) and inter-assay variation (variation between replicates from different experiments) were evaluated to determine the repeatability and reproducibility of the assay for detecting and quantifying total $V$. cholerae and its $\mathrm{O} 1$ serogroup subpopulation. Precision analysis to test random variation of repeated measurements was done for this assay by calculating the coefficient of variation $(\% \mathrm{CV})$ of multiple replicates of standards run in the same experiment and experiments on different days. Intra-assay \%CV ranged from 0.01 to $0.05 \%$ for the $v i u B$ assay and 0.01 to $0.03 \%$ for the $r f b O 1$ assay. Inter-assay $\% \mathrm{CV}$ ranged from 0.07 to $0.20 \%$ for $v i u B$ and 0.03 to $0.21 \%$ for $r f b O 1$ (TABLE 2). The efficiency of both 
assays was $100 \%$ based on the standard curve generated from a serial dilution of $V$. cholerae N16961 (FIGURE 2) with $\mathrm{R}^{2}=0.99$ and slope of -3.3 .

To test for qPCR inhibition, we compared the quantitative cycle value $(\mathrm{Cq})$ values for different dilutions of filter-sterilized environmental water samples spiked with the reference $V$. cholerae strains. The $10 \times$ diluted samples shifted the $\mathrm{Cq}$ values by $3.3 \pm 0.07$ cycles (TABLE S1), indicating no significant inhibition.

\subsection{Analysis of environmental water samples}

With this field-ready method, it was possible to quantify the abundance of both total $V$. cholerae and $V$. cholerae $\mathrm{O} 1$ in the same experiment (FIGURE 3). Five mL of environmental water samples were concentrated to $100 \mu \mathrm{L}$, from which $10 \mu \mathrm{L}$ was used in the qPCR amplification. Each reaction was run in triplicate. The abundance of $V$. cholerae in the water samples collected from the Gabtoli area, Dhaka, Bangladesh was between $3.7 \times 10^{4}$ to 3.9 $\times 10^{4}$ genome copies/L (FIGURE 4). V. cholerae O1 was found at $4.7 \times 10^{3}$ to $5.4 \times 10^{3}$ genome copies/L, representing approximately $13 \%$ of the total $V$. cholerae population (FIGURE 4 ).

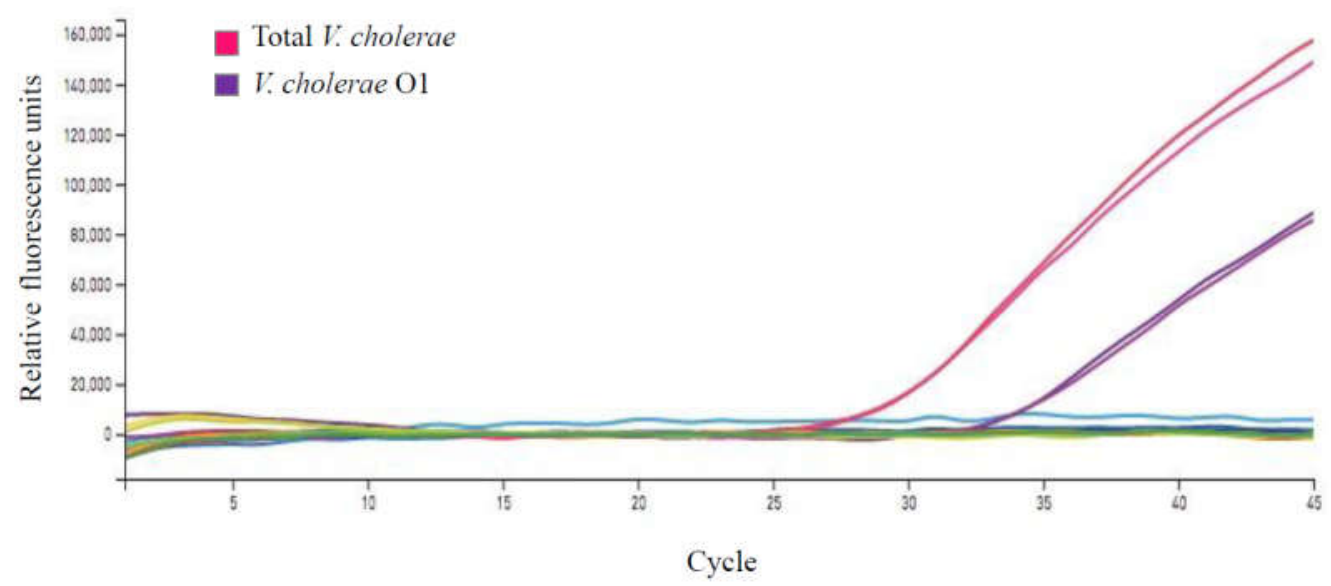

Figure 3. Detection and quantification of total $V$. cholerae and V. cholerae $\mathrm{O} 1$ in the same qPCR experiment. Filter-sterilized environmental water samples collected from the Gabtoli site were inoculated with known concentrations of cells of reference strain V. cholerae N16961 El Tor O1. Quantification was performed with both $v i u B$ and $r f b O 1$ primers in the same PCR run to detect total $V$. cholerae and $\mathrm{O} 1$ serogroup $V$. cholerae, respectively.

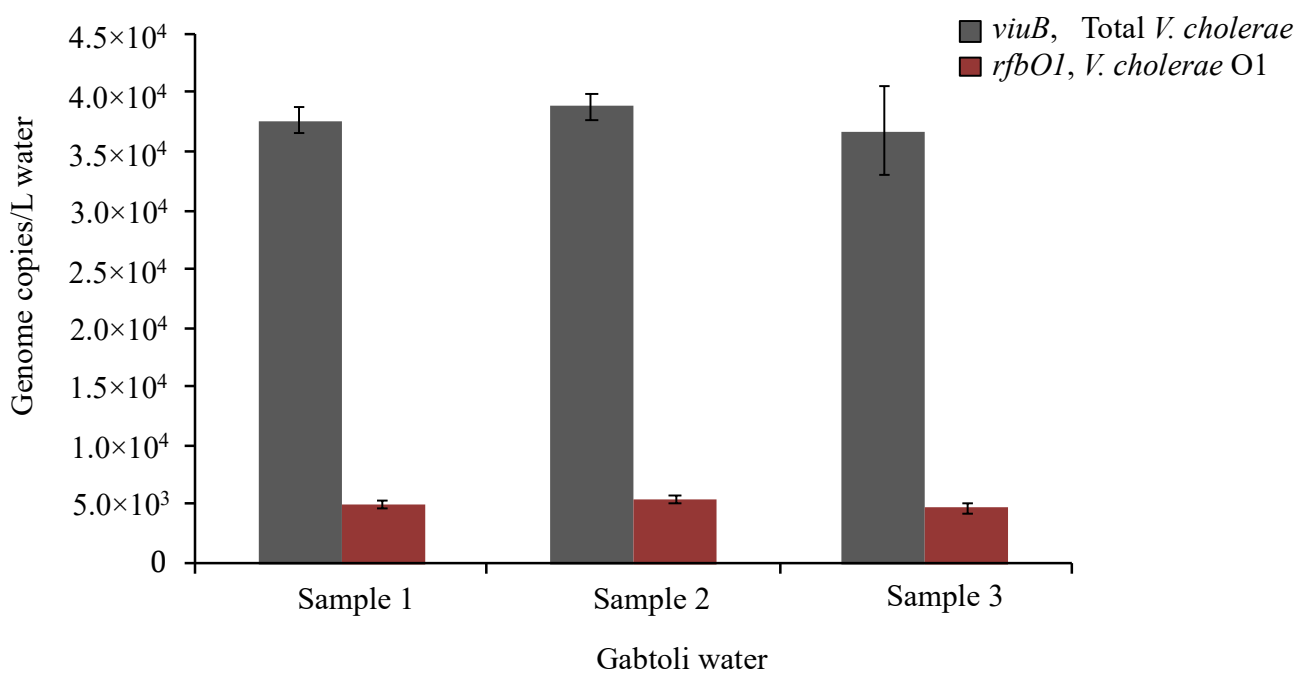

Figure 4. Abundance of $V$. cholerae along with its $\mathrm{O} 1$ serogroup subpopulation in water from an inland urban region (Gabtoli, Dhaka) of Bangladesh. Water samples were collected in August 2018 and analyzed using the developed qPCR assay. The viuB gene marker was used to quantify total $V$. cholerae, and $r f b O 1$ was used to quantify $V$. cholerae O1. Each qPCR reaction was run in 
triplicate and evaluated with corresponding standards. Error bars represent the standard deviation of means from biological replicates.

\section{Discussion}

Since cholera is a waterborne infectious disease and the primary mode of transmission is via the fecal-oral route, environmental water bodies serve as an inevitable reservoir for pathogenic $V$. cholerae. This bacterium is associated with plankton mainly in brackish waters and is ubiquitous in temperate and tropical estuarine microbial communities [61]. As a survival strategy, $V$. cholerae goes into a viable but non-culturable state (VBNC) under unfavorable environmental conditions, in which it assumes a coccoid shape and cannot be revived using traditional culturing methods [21,62]. Non-culturable $V$. cholerae in biofilm were reported in environmental water samples from Mathbaria (Bangladesh), and were able to resume active growth after passage through the gastrointestinal tract of rabbits (in animal passage of non-culturable $V$. cholerae O1) following a period of more than a year in a microcosm [63]. Therefore, passing through the human host could be a means of revival from the VBNC state, contributing to the amplification of $V$. cholerae prior to an outbreak $[64,65]$ and its subsequent transmission through the fecal-oral route due to poor management of drinking water and hygiene. This survival state frequently found in the environment for $V$. cholerae means that water bodies can serve as a long-term reservoir for this pathogen, leading to the consistent and persistent pattern of cholera epidemics historically documented on the coast of Bangladesh. There is also recent evidence that indicates that environmental $V$. cholerae may play a role in reviving VBNCs through the over production of products associated with quorum sensing [35]. As the body of literature regarding environmental $V$. cholerae increases $[12,17,24,66]$, we expect the interactions between pathogenic and non-pathogenic $V$. cholerae to be resolved in greater detail.

The ability of $V$. cholerae to exist in a VBNC state has hindered our ability to quantify it in environmental reservoirs using traditional methods. Limited resources and lack of infrastructure in countries where cholera is endemic has also increased the challenge in monitoring its causative agent. The qPCR method developed here allows the detection and quantification of $V$. cholerae and the $\mathrm{O} 1$ serogroup strains responsible for most outbreaks. Furthermore, the portable and low-cost instrument used (Chai Open qPCR), as well as our streamlined protocol, allow processing of water samples on site, without the need for DNA extraction or any pre-enrichment procedure. The main challenge for direct quantification is that the number of bacteria in environmental water is usually below the LOD of existing qPCR methods [67]. However, this problem was overcame by increasing the concentration of the water sample 50-fold using simple size-exclusion centrifugation.

The targeted $v i u B$ gene sequence is only present in $V$. cholerae and can be amplified from both $\mathrm{O} 1$ and non-O1 strains. Moreover, $V$. cholerae $\mathrm{O} 1$ could be detected with primers targeting the $r f b O 1$ gene, thus allowing the determination of the abundance of both populations with $100 \%$ specificity. The assay sensitivity was as low as three copies per reaction, which is expected for a well-designed and sensitive assay, as described in the MIQE guidelines [68]. The limit of detection for concentrated water samples was $5 \times 10^{3} \mathrm{CFU} / \mathrm{L}$, which is at the lower limit of an infectious dose of $V$. cholerae, reported to be $10^{3}-10^{9}$ cells based on a range of factors, such as the health of the exposed individual [69]. More specifically, the infectious dose for toxigenic $V$. cholerae $\mathrm{O} 1$ is typically around $10^{4}-10^{6}$ cells, whereas the infective dose for non-O1 strains is around $10^{6}-10^{9}[70]$. Without the concentration procedure, the limit of detection of $V$. cholerae in environmental water samples would be $3 \times 10^{6} \mathrm{CFU} / \mathrm{L}$, which is still useful to determine if a strong risk of contracting cholera exists. This assay determines the absolute abundance of both $V$. cholerae $\mathrm{O} 1$ and non-O1 in parallel qPCR reactions and thus is very useful to calculate the proportion of toxigenic $V$. cholerae $\mathrm{O} 1$ in a particular geographical location. Therefore, this assay is useful to track cholera in endemic areas like Bangladesh, where all detected $V$. cholerae O1 strains were found to be toxigenic [63,71].

The possibility of storing the qPCR master mix on ice $\left(4^{\circ} \mathrm{C}\right)$ for extended periods of time and the portable feature of the Chai thermocycler (small footprint of $28 \mathrm{~cm} \times 24 \mathrm{~cm}$, 
weight of $4 \mathrm{~kg}$ ) facilitates the use of this method in field-level surveillance and also avoids transportation problems leading to deterioration of the samples. The convenient set up of the whole procedure makes this assay workable in most resource-limited settings. Moreover, quick processing of the sample reduces the chance of cross-contamination.

As proof of concept, we analyzed water samples collected from the river basin of the Turag River in a region endemic for cholera, the Gabtoli area of Dhaka, Bangladesh. Approximately 25,000 people live in this area, which is surrounded by brickfields with high traffic [72]. This site was chosen as previous studies indicated the presence of $V$. cholerae $\mathrm{O} 1$ and cholera infections are often detected in people living in the surrounding area [73]. The number of total $V$. cholerae detected was about $3.9 \times 10^{4}$ genome copies/L, $13 \%$ of which was $V$. cholerae $\mathrm{O} 1\left(\sim 5 \times 10^{3}\right.$ genome copies/L). This is of concern as it is within the range of the infectious dose for cholera if someone were to ingest a few hundred milliliters of water ( $>10^{3}$ cells) [69]. Previous studies based on the Crystal VC ${ }^{\circledR}$ dipstick test after sample enrichment for 18 hours in alkaline peptone water showed that in urban Dhaka, Bangladesh, $30 \%$ of water sources used by households of cholera patients were contaminated with $V$. cholerae [74,75]. From our observations during sampling, which are also reported by other studies, the water bodies around Dhaka city serve as drinking water sources and are frequently used for domestic purposes, such as washing utensils and bathing [76]. It is therefore likely that local rivers and ponds serve as important reservoirs of the cholera pathogen in Dhaka city. The importance of local ecosystems in maintaining toxigenic cholera is known $[77,78]$, but because of the difficulty in monitoring at sufficient frequency in a number of locations, a direct link has never been established between a rise in $V$. cholerae numbers and the start of a seasonal epidemic, despite the timing of these being well known from the tracking of cholerae cases in hospitals.

Many qPCR assays for the quantification of $V$. cholerae have been previously developed, but all of them require modern laboratory facilities and are not amenable to extensive field studies. Furthermore, there is not a single study of the environmental tracking of $V$. cholerae in a cholera-endemic setting of significant size. With the currently available techniques, either spiked environmental samples were evaluated after pre-enrichment in alkaline peptone water or DNA extraction after filtration [13,79]. Amongst these methods, culture-based techniques are still the most frequently used and only reveal a small proportion of naturally occurring bacterial populations in water samples. These methods do not capture coccoid non-culturable cells within clusters of biofilms in estuarine environments present in Bangladesh water bodies during the period between outbreaks when reported cases of cholera are low [80].

Another widely used method is dipstick, which is valuable to detect $V$. cholerae $\mathrm{O} 1$ and $\mathrm{O} 139$ in both water and stool samples. This is a rapid and inexpensive method, but has a limit of detection of $10^{7} \mathrm{CFU}$ of enriched culture that is higher than the usual infectious dose of cholera [69]. This method only provides a qualitative output and requires six hours of enrichment before testing. Also, because of compromised sensitivity, it was recommended for use in combination with a traditional bacterial culture method [74].

Our assay is specific, sensitive, and convenient for field studies, making it possible to overcome the limitations of current "rapid" techniques. In this study, a single channel Chai thermocycler was used, which only permitted FAM to be used as a fluorescein dye. A dual channel Chai system also exists, where HEX or VIC fluorescein dyes can also be used with FAM, making a multiplex qPCR assay possible. Thus, it is possible to optimize a multiplex assay where $V$. cholerae $\mathrm{O} 1$ can be rapidly identified and quantified simultaneously in a single reaction along with total $V$. cholerae.

During the environmental sample analysis, we did not find significant inhibition to PCR amplification in our assay. However, for testing water from more contaminated sources, as determined by multivariate analysis of environmental factors where the industrial waste disposal and high population density matters $[81,82]$, further treatment of the sample to remove inhibitors may be required. A study on water quality assessment of the roadside surface of Savar, Dhaka explained the impact of vehicle emission, atmospheric deposition from brick field, industrial pollution and massive urbanization on the 
water reservoirs as total suspended solids ( $>25 \mathrm{mg} / \mathrm{L})$, total dissolved solids ( $>840 \mathrm{mg} / \mathrm{L})$, biological oxygen demands $(0.758 \mathrm{mg} / \mathrm{L})$, dissolved oxygen $(4.5 \mathrm{mg} / \mathrm{L})$ were high or even higher than the standards [72].

In conclusion, we developed a species-specific qPCR method, which can be conveniently used at the sampling site without any need for pre-enrichment or DNA extraction. This test can support a continuous monitoring program for $V$. cholerae $\mathrm{O} 1$ in water reservoirs used by residents, which in coordination with local authorities could limit risks of contracting cholera and allow the identification of sources of contamination.

\section{Materials and Methods}

\subsection{Preparation of bacterial cultures}

Forty-six different strains of Vibrio spp. and other gammaproteobacteria were used to validate analytical sensitivity and specificity of the assay in this study (TABLE 1). Seventeen non-O1 $V$. cholerae from environmental sources, eight $V$. cholerae $\mathrm{O} 1$ from both clinical and environmental sources, and ten $V$. metoecus from environmental sources were tested (TABLE 1). Multiple strains from three other Vibrio species [V. parahaemolyticus (1), $V$. vulnificus (2) and V. mimicus (3)] were tested along with two strains of Pseudomonas aeruginosa and Escherichia coli each. The Vibrio strains were grown in tryptic soy broth (TSB) (Becton Dickinson) with $1.0 \% \mathrm{NaCl}(\mathrm{BDH})$ at $30^{\circ} \mathrm{C}$ and $200 \mathrm{rpm}$ overnight in a shaking incubator.

\subsection{Collection and processing of environmental samples}

Environmental water samples were collected from the river basin of the Turag river in the Gabtoli area (the coordinates of the latitude and longitude are 23.783726, 90.344246) [83] of Dhaka, Bangladesh (FIGURE 1) during August 2018. Three locations, approximately 5 meters apart from each other, were chosen at this site and water samples were collected in triplicate from each of those locations (nine samples in total). Five milliliters of surface water was collected directly in Thermo Scientific Nunc $50 \mathrm{~mL}$ conical centrifuge tubes (Thermo Fisher Scientific, Korea). When needed, collected water samples were concentrated using Amicon Ultra-0.5 centrifugal filter device (Merk KGaA, Darmstadt, Germany) (FIGURE 5) according to the user's manual. Ten Amicon tubes, each containing 500 $\mu \mathrm{L}$ of water sample, were centrifuged at $14000 \times \mathrm{g}$ for $20 \mathrm{mins}$ in a mini spin plus centrifuge (Eppendorf, Germany). All the concentrates were pooled. Altogether, $5 \mathrm{~mL}$ of water from each of the three replicates from each of three locations were concentrated to $100 \mu \mathrm{L}$.

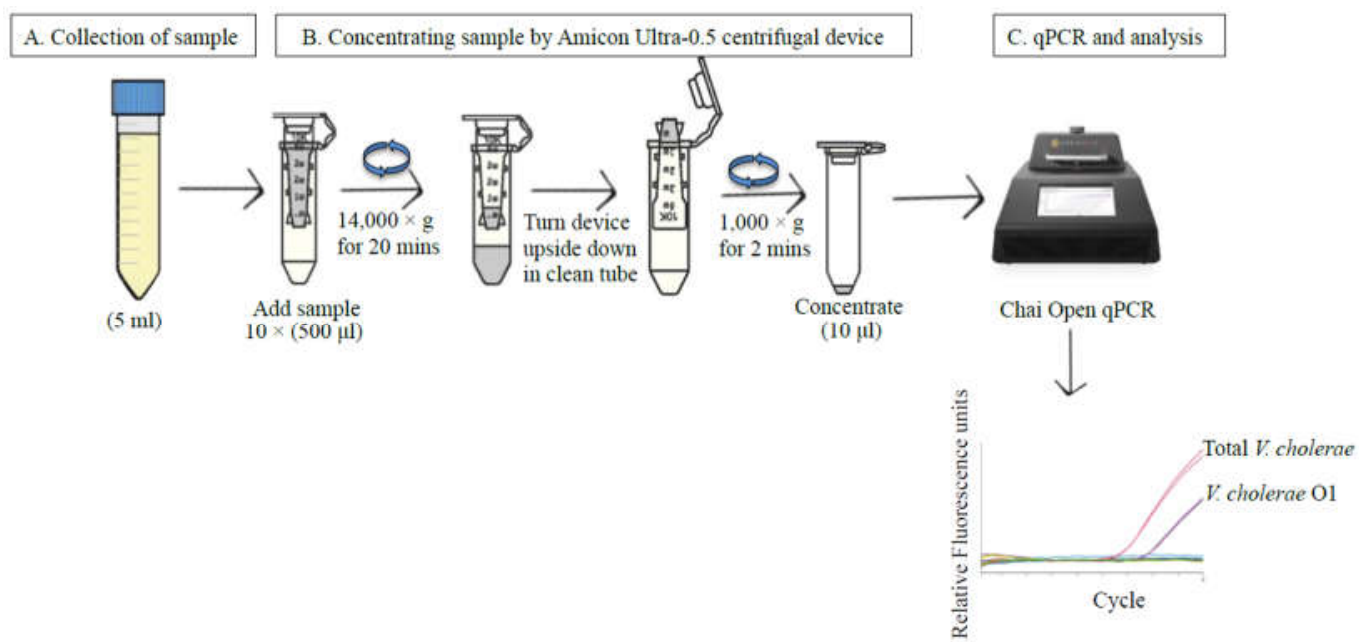

Figure 5. Method for processing of environmental samples for qPCR. (A) Sample collection. (B) Concentrating sample by Amicon Ultra- 0.5 centrifugal device. (C) qPCR in the Chai Open qPCR thermocycler (https://www.chaibio.com/openqpcr) $5 \mathrm{~mL}$ of water was collected from each location. Ten Amicon tubes, each with $500 \mu \mathrm{L}$ of water sample, were centrifuged at $14000 \times \mathrm{g}$ for 20 minutes in a 
mini spin plus centrifuge, and all the concentrates were pooled in a total volume of concentrate of $100 \mu \mathrm{L}$.

\subsection{Amplification using the Chai open qPCR platform}

Previously developed species-specific primers [73] were used to detect and quantify $V$. cholerae in this assay. Briefly, the viuB gene encoding vibriobactin utilization protein $B$ was used to quantify total $V$. cholerae (all serogroups), as it is a single copy gene present in all $V$. cholerae with only divergent homologs present in other species. To detect and quantify $V$. cholerae from the $\mathrm{O} 1$ serogroup, we used specific primers and probe to amplify the $r f b O 1$ gene essential for the synthesis of this antigen (TABLE 3) [73]. For this study, the reporter dye 56-FAM (Fluorescein) was used for both probe sets as this qPCR assay was optimized in the Chai Open qPCR thermocycler (CHAI, USA) which has a single channel to detect wavelengths of 513-555 $\mathrm{nm}$.

Table 3. Target genes and sequences of primers and probes used in this study

\begin{tabular}{|c|c|c|c|c|}
\hline $\begin{array}{l}\text { Target } \\
\text { gene }\end{array}$ & $\begin{array}{c}\text { Primer } \\
\text { and probe }\end{array}$ & Sequence $\left(5^{\prime}-3^{\prime}\right)$ & $\begin{array}{l}\text { Amplicon } \\
\text { size (bp) }\end{array}$ & References \\
\hline \multirow[t]{3}{*}{$\operatorname{viu} B$} & Probe & 56-FAM/TCATTTGGC/ZEN/CAGAGCATAAACCGGT/3IABkFQ & 77 & [73] \\
\hline & $\begin{array}{l}\text { Forward } \\
\text { primer }\end{array}$ & TCGGTATTGTCTAACGGTAT & & \\
\hline & $\begin{array}{l}\text { Reverse } \\
\text { Primer }\end{array}$ & CGATTCGTGAGGGTGATA & & \\
\hline \multirow[t]{3}{*}{$r f b O 1$} & Probe & 56-FAM/AGAAGTGTG/ZEN/TGGGCCAGGTAAAGT/3IABkFQ & 113 & [73] \\
\hline & $\begin{array}{l}\text { Forward } \\
\text { primer }\end{array}$ & GTAAAGCAGGATGGAAACATATTC & & \\
\hline & $\begin{array}{l}\text { Reverse } \\
\text { primer }\end{array}$ & TGGGCTTACAAACTCAAGTAAG & & \\
\hline
\end{tabular}

Dynamite qPCR Master mix used in this study is a proprietary mix, developed and distributed by the Molecular Biology Service Unit (University of Alberta, Canada). It contains Tris (pH 8.3), KCL, $\mathrm{MgCl}_{2}$, glycerol, Tween 20, DMSO, dNTPs, ROX as a normalizing dye and antibody inhibited Taq polymerase. The volume of each PCR reaction was $50 \mu \mathrm{L}$, which contained $25 \mu \mathrm{L}$ of $2 \times$ Dynamite qPCR master mix, $5 \mu \mathrm{L}$ of $500 \mathrm{nM}$ primer- $250 \mathrm{nM}$ probe mix, $10 \mu \mathrm{L}$ of molecular grade water and $10 \mu \mathrm{l}$ of the concentrated environmental water sample. The recommended long-term storage temperature for this master mix is $4^{\circ} \mathrm{C}$. Conditions for the real-time qPCR are as follows: initial activation of the enzyme at $95^{\circ} \mathrm{C}$ for $2 \mathrm{~min}$ followed by 45 cycles of $95^{\circ} \mathrm{C}$ for $30 \mathrm{~s}, 60^{\circ} \mathrm{C}$ for $1 \mathrm{~min}$ in the Chai Open qPCR system. In this qPCR method, the detection and quantification of the viuB and $r f b O 1$ gene markers were carried out in parallel in separate tubes but in the same thermocycler run. Standards of a known number of cells and no template control were included in every assay.

\subsection{Standard curve for the qPCR assay}

Standard curves were generated using the $V$. cholerae El Tor O1 N16961 reference strain. Pure bacterial culture was grown on LB agar (Becton Dickinson) at $30^{\circ} \mathrm{C}$ overnight. Bacteria were then diluted in sterile water prepared by filtering $50 \mathrm{~mL}$ of water from the study location pushed through a $0.2 \mu \mathrm{m}$ PES filter media (Whatman, GE Healthcare, UK) using a $50 \mathrm{~mL}$ syringe (BD, USA). A series of standards were prepared in which bacterial cells were present at $3 \times 10^{5}$ copies, $3 \times 10^{4}$ copies, $3 \times 10^{3}$ copies, $3 \times 10^{2}$ copies, 30 copies and 3 copies per $10 \mu \mathrm{L}$ of filter sterilized water. Inoculum concentration were quantified 
using a standard drop plate method [84]. Standards were run in three independent experiments, with three replicates per dilution and repeated on three different days. The average of each experiment was assessed to define intra- and inter-assay variation (TABLE 2). A standard curve was generated by plotting the log value of the calculated CFU per reaction against the $\mathrm{Cq}$. The $\mathrm{Cq}$ value is the cycle at which the fluorescence from amplification exceeded the background fluorescence in the MIQE guidelines [68].

\subsection{Determination of the LOD and qPCR efficiency}

The LOD of the assay was determined from the standard curve constructed from serially diluted standards of $V$. cholerae N16961 as mentioned above (FIGURE 2). To determine the LOD of samples which were concentrated, known numbers of $V$. cholerae N16961 were spiked in filter sterilized environmental water samples collected from the same location (Gabtoli, Dhaka) and subjected to the same concentration protocol as environmental samples using the Amicon ultra- 0.5 centrifugal filter device. $1 \mathrm{~mL}$ of spiked environmental water sample was concentrated to $20 \mu \mathrm{L}$ after 30 mins of spinning. The qPCR assay was carried out on these concentrated samples containing known bacterial cell numbers in the Chai Open qPCR system (TABLE S1). Cq values were used to define LOD of the assay. The LOD typically is assumed to be the highest $\mathrm{Cq}$ value observed for the lowest concentration that can be determined based on the dilution at which all replicates were positive across ten repeated experiments.

The qPCR efficiency of the assay was calculated using the following formula: Efficiency $=10[-1 /$ Slope $][13,85]$ in Excel.

Supplementary Materials: The following supporting information can be downloaded at: www.mdpi.com/xxx/s1, Supplementary Table S1: Determination of limit of detection of sample after concentrating step and testing inhibition in the assay.

Author Contributions: T.N.; conceptualization, methodology, formal analysis, investigation, data curation, writing - original draft preparation, visualization, N.A.S.H., J.Y.H and V.Z.J.A; writing review and editing, M.A.; methodology, S.K.Y.; conceptualization, supervision, writing - review and editing, resources, Y.F.B. - conceptualization, resources, writing - review and editing, supervision, project administration, funding acquisition. All authors have read and agreed to the published version of the manuscript.

Funding: This research was funded by Natural Sciences and Engineering Research Council of Canada (NSERC), grant number RGPIN-2020-04422 and the Integrated Microbial Biodiversity program of the Canadian Institute for Advanced Research to Y.F.B. We also acknowledge the support of graduate student scholarships from NSERC (to T.N.), Alberta Innovates Technology Futures (to T.N.) and Faculty of Graduate Studies and Research at the University of Alberta (to T.N. and N.A.S.H.), the Department of Biological Sciences at the University of Alberta (to N.A.S.H.), and Alberta Advanced Education (to N.A.S.H.).

Data Availability Statement: Data is contained within the article or supplementary material.

Acknowledgments: We thank David Alton (Chief Operating Officer, Aquila Diagnostic System Inc.) for letting us to use the Chai Open qPCR Thermocycler in their research facility at National Institute for Nanotechnology (NINT) in University of Alberta. MA of ICDDR, b thanks the government of Bangladesh, Canada, Sweden and United Kingdom for providing unrestricted core support.

Conflicts of Interest: The authors declare no conflict of interest.

\section{References}

1. Huang, J.; Zhu, Y.; Wen, H.; Zhang, J.; Huang, S.; Niu, J.; Li, Q. Quadruplex real-time PCR assay for detection and identification of Vibrio cholerae $\mathrm{O} 1$ and $\mathrm{O} 139$ strains and determination of their toxigenic potential. Appl Environ Microbiol 2009, 75, 6981-6985.

2. Albert, M.J.; Siddique, A.K.; Islam, M.S.; Faruque, A.S.; Ansaruzzaman, M.; Faruque, S.M.; Sack, R.B. Large outbreak of clinical cholera due to Vibrio cholerae non-O1 in Bangladesh. Lancet 1993, 341, 704. 
3. Bakhshi, B.; Barzelighi, H.M.; Adabi, M.; Lari, A.R.; Pourshafie, M. A molecular survey on virulence associated genotypes of non-O1 non-O139 Vibrio cholerae in aquatic environment of Tehran, Iran. Water research 2009, 43, 1441-1447.

4. Chhotray, G.; Pal, B.; Khuntia, H.; Chowdhury, N.; Chakraborty, S.; Yamasaki, S.; Ramamurthy, T.; Takeda, Y.; Bhattacharya, S.; Nair, G.B.J.E.; et al. Incidence and molecular analysis of Vibrio cholerae associated with cholera outbreak subsequent to the super cyclone in Orissa, India. 2002, 128, 131-138.

5. Jesudason, M.; Samuel, R.; John, T.J. Reappearance of Vibrio cholerae 01 and concurrent prevalence of 01 and 0139 in Vellore, South India. The Lancet 1994, 344, 335-336.

6. European Centre for Disease Prevention and Control (ECDC). Cholera worldwide overview. Available online: https://www.ecdc.europa.eu/en/all-topics-z/cholera/surveillance-and-disease-data/cholera-monthly (accessed on 13th February).

7. Centers for Disease Control and Prevention, N.C.f.E.a.Z.I.D.N., Division of Foodborne, Waterborne, and Environmental Diseases (DFWED). Cholera - Vibrio cholerae infection. Available online: https://www.cdc.gov/cholera/general/index.html (accessed on 13th February).

8. WHO. Ending Cholera - A Global Roadmap to 2030; 2019; pp. 1-32.

9. Ratnayake, R.; Finger, F.; Edmunds, W.J.; Checchi, F. Early detection of cholera epidemics to support control in fragile states: estimation of delays and potential epidemic sizes. BMC Med 2020, 18, 397, doi:10.1186/s12916-020-01865-7.

10. Reuters. Yemen cholera outbreak accelerates to 10,000+ cases per week: WHO. Reuters 2018.

11. WHO. Cholera situation in Yemen, December 2020; 2021.

12. Bliem, R.; Schauer, S.; Plicka, H.; Obwaller, A.; Sommer, R.; Steinrigl, A.; Alam, M.; Reischer, G.H.; Farnleitner, A.H.; Kirschner, A. A novel triplex quantitative PCR strategy for quantification of toxigenic and nontoxigenic Vibrio cholerae in aquatic environments. Appl Environ Microbiol 2015, 81, 3077-3085, doi:10.1128/AEM.03516-14.

13. Blackstone, G.M.; Nordstrom, J.L.; Bowen, M.D.; Meyer, R.F.; Imbro, P.; DePaola, A. Use of a real time PCR assay for detection of the ctxA gene of Vibrio cholerae in an environmental survey of Mobile Bay. J Microbiol Methods 2007, 68, 254-259, doi:10.1016/j.mimet.2006.08.006.

14. Islam, M.; Hasan, M.; Miah, M.; Yunus, M.; Zaman, K.; Albert, M. Isolation of Vibrio cholerae O139 synonym Bengal from the aquatic environment in Bangladesh: implications for disease transmission. Appl Environ Microbiol 1994, 60, $1684-1686$.

15. Ramamurthy, T.; Garg, S.; Sharma, R.; Bhattacharya, S.; Nair, G.B.; Shimada, T.; Takeda, T.; Karasawa, T.; Kurazano, H.; Pal, A.J.T.L. Emergence of novel strain of Vibrio cholerae with epidemic potential in southern and eastern India. 1993, 341, 703704.

16. Islam, M.T.; Alam, M.; Boucher, Y. Emergence, ecology and dispersal of the pandemic generating Vibrio cholerae lineage. Int Microbiol 2017, 20, 106-115.

17. Bliem, R.; Reischer, G.; Linke, R.; Farnleitner, A.; Kirschner, A. Spatiotemporal dynamics of Vibrio cholerae in turbid alkaline lakes as determined by quantitative PCR. Applied and environmental microbiology 2018, 84, e00317-00318.

18. Glass, R.I.; Becker, S.; Huq, M.I.; Stoll, B.J.; Khan, M.; Merson, M.H.; Lee, J.V.; Black, R.E. Endemic cholera in rural Bangladesh, 1966-1980. American journal of epidemiology 1982, 116, 959-970.

19. Kaper, J.; Morris, J.L.M. Cholera. Clin Microbiol Rev 1995, 8, 48-86.

20. Faruque, S.M.; Albert, M.J.; Mekalanos, J.J. Epidemiology, genetics, and ecology of toxigenic vibrio cholerae. Microbiol Mol Biol Rev 1998, 62, 1301-1314.

21. Colwell, R.R. Viable but nonculturable bacteria: a survival strategy. J Infect Chemother 2000, 6, 121-125, doi:10.1007/s101560000026.

22. Huq, A.; Colwell, R.R.; Chowdhury, M.A.R.; Xu, B.; Moniruzzaman, S.M.; Islam, M.S.; Yunus, M.; Albert, M.J. Coexistence of Vibrio cholerae 01 and 0139 Bengal in plankton in Bangladesh. The Lancet 1995, 345, 1249.

23. Epstein, P.R. Algal blooms in the spread and persistence of cholera. Biosystems 1993, 31, $209-221$. 
24. Islam, M.S.; Zaman, M.H.; Islam, M.S.; Ahmed, N.; Clemens, J.D. Environmental reservoirs of Vibrio cholerae. Vaccine 2020, 38, A52-A62.

25. Lee, K. The global dimensions of cholera. Global change and human health 2001, 2, 6-17.

26. Piarroux, R.; Barrais, R.; Faucher, B.; Haus, R.; Piarroux, M.; Gaudart, J.; Magloire, R.; Raoult, D. Understanding the cholera epidemic, Haiti. Emerging infectious diseases 2011, 17, 1161.

27. Zuckerman, J.N.; Rombo, L.; Fisch, A. The true burden and risk of cholera: implications for prevention and control. The Lancet infectious diseases 2007, 7, 521-530.

28. Orata, F.D.; Keim, P.S.; Boucher, Y. The 2010 cholera outbreak in Haiti: how science solved a controversy. PLoS Pathog 2014, 10, e1003967.

29. Guillaume, Y.; Ternier, R.; Vissieres, K.; Casseus, A.; Chery, M.J.; Ivers, L.C. Responding to cholera in haiti: Implications for the national plan to eliminate cholera by 2022. The Journal of infectious diseases 2018, 218, S167-S170.

30. Pan American Health Organization (PAHO). Haiti reaches one-year free of Cholera. Available online: https://www3.paho.org/hq/index.php?option=com_content\&view=article\&id=15684:haiti-reaches-one-year-free-ofcholera\&Itemid=1926\&lang=en (accessed on 28th Jan ).

31. Satcher, D. Emerging infections: getting ahead of the curve. Emerg Infect Dis 1995, 1, 1.

32. Poirier, M.J.; Izurieta, R.; Malavade, S.S.; McDonald, M.D. Re-emergence of Cholera in the Americas: Risks, Susceptibility, and Ecology. J Glob Infect Dis 2012, 4, 162-171, doi:10.4103/0974-777X.100576.

33. Almagro-Moreno, S.; Taylor, R.K. Cholera: environmental reservoirs and impact on disease transmission. Microbiology spectrum 2013, 1.2 .

34. Colwell, R.; Brayton, P.; Grimes, D.; Roszak, D.; Huq, S.; Palmer, L. Viable but non-culturable Vibrio cholerae and related pathogens in the environment: implications for release of genetically engineered microorganisms. Nature biotechnology 1985, 3,817 .

35. Naser, I.B.; Shishir, T.A.; Faruque, S.N.; Hoque, M.M.; Hasan, A.; Faruque, S.M. Environmental prevalence of toxigenic Vibrio cholerae $\mathrm{O} 1$ in Bangladesh coincides with V. cholerae non-O1 non-O139 genetic variants which overproduce autoinducer-2. PLoS One 2021, 16, e0254068, doi:10.1371/journal.pone.0254068.

36. Hasan, J.; Huq, A.; Tamplin, M.L.; Siebeling, R.J.; Colwell, R.R. A novel kit for rapid detection of Vibrio cholerae O1. J Clin Microbiol 1994, 32, 249-252.

37. Colwell, R.R. Nonculturable but still viable and potentially pathogenic. Zentbl. Bacteriol. 1993, $279,154-158$.

38. Benenson, A.S.; Islam, M.R.; Greenough Iii, W.B. Rapid identification of Vibrio cholerae by darkfield microscopy. Bulletin of the World Health Organization 1964, 30, 827.

39. Alam, M.; Hasan, N.A.; Sultana, M.; Nair, G.B.; Sadique, A.; Faruque, A.; Endtz, H.P.; Sack, R.; Huq, A.; Colwell, R. Diagnostic limitations to accurate diagnosis of cholera. Journal of clinical microbiology 2010, 48, 3918-3922.

40. Almeida, R.; Hickman-Brenner, F.; Sowers, E.; Puhr, N.; Farmer, J.; Wachsmuth, I. Comparison of a latex agglutination assay and an enzyme-linked immunosorbent assay for detecting cholera toxin. Journal of clinical microbiology 1990, 28, 128-130.

41. Harris, J.R.; Cavallaro, E.C.; De Nóbrega, A.A.; Dos S. Barrado, J.C.; Bopp, C.; Parsons, M.B.; Djalo, D.; Fonseca, F.G.d.S.; Ba, U.; Semedo, A. Field evaluation of Crystal VC® Rapid Dipstick test for cholera during a cholera outbreak in Guinea-Bissau. Tropical medicine international health 2009, 14, 1117-1121.

42. Moyenuddin, M.; Rahman, K.M.; Sack, D.A. The aetiology of diarrhoea in children at an urban hospital in Bangladesh. Transactions of the Royal Society of Tropical Medicine Hygiene 1987, 81, 299-302.

43. Xu, H.-S.; Roberts, N.; Adams, L.; West, P.; Siebeling, R.; Huq, A.; Huq, M.; Rahman, R.; Colwell, R. An indirect fluoresent antibody staining procedure for detection of Vibrio cholerae serovar 01 cells in aquatic environmental samples. Journal of Microbiological Methods 1984, 2, 221-231. 
44. Rudko, S.P.; Reimink, R.L.; Peter, B.; White, J.; Hanington, P.C. Democratizing water monitoring: Implementation of a community-based qPCR monitoring program for recreational water hazards. PLoS One 2020, 15, e0229701, doi:10.1371/journal.pone.0229701.

45. Kirchberger, P.C.; Orata, F.D.; Barlow, E.J.; Kauffman, K.M.; Case, R.J.; Polz, M.F.; Boucher, Y. A small number of phylogenetically distinct clonal complexes dominate a coastal Vibrio cholerae population. Appl Environ Microbiol 2016, AEM. 01177-01116.

46. Heidelberg, J.F.; Eisen, J.A.; Nelson, W.C.; Clayton, R.A.; Gwinn, M.L.; Dodson, R.J.; Haft, D.H.; Hickey, E.K.; Peterson, J.D.; Umayam, L. DNA sequence of both chromosomes of the cholera pathogen Vibrio cholerae. Nature 2000, 406, 477.

47. Chun, J.; Grim, C.J.; Hasan, N.A.; Lee, J.H.; Choi, S.Y.; Haley, B.J.; Taviani, E.; Jeon, Y.S.; Kim, D.W.; Lee, J.H.; et al. Comparative genomics reveals mechanism for short-term and long-term clonal transitions in pandemic Vibrio cholerae. Proc Natl Acad Sci U S A 2009, 106, 15442-15447, doi:10.1073/pnas.0907787106.

48. Yang, N.; Liu, M.; Luo, X.; Pan, J. Draft genome sequence of Strain ATCC 17802(T), the type strain of Vibrio parahaemolyticus. Mar Genomics 2015, 24 Pt 3, 203-205, doi:10.1016/j.margen.2015.05.010.

49. Li, Z.; Chen, H.; Chen, X.; Zhou, T.; Zhao, L.; Zhang, C.; Jin, W. Genome sequence of the human-pathogenic bacterium Vibrio vulnificus type strain ATCC 27562. J Bacteriol 2012, 194, 6954-6955, doi:10.1128/JB.01890-12.

50. Stine, O.C.; Sozhamannan, S.; Gou, Q.; Zheng, S.; Morris, J.G., Jr.; Johnson, J.A. Phylogeny of Vibrio cholerae based on recA sequence. Infect Immun 2000, 68, 7180-7185, doi:10.1128/IAI.68.12.7180-7185.2000.

51. Fouz, B.; Roig, F.J.; Amaro, C. Phenotypic and genotypic characterization of a new fish-virulent Vibrio vulnificus serovar that lacks potential to infect humans. Microbiology (Reading) 2007, 153, 1926-1934, doi:10.1099/mic.0.2006/005405-0.

Haley, B.J.; Grim, C.J.; Hasan, N.A.; Choi, S.-Y.; Chun, J.; Brettin, T.S.; Bruce, D.C.; Challacombe, J.F.; Detter, J.C.; Han, C.S. Comparative genomic analysis reveals evidence of two novel Vibrio species closely related to V. cholerae. BMC Microbiol 2010, 10, 154.

53. Kirchberger, P.C.; Turnsek, M.; Hunt, D.E.; Haley, B.J.; Colwell, R.R.; Polz, M.F.; Tarr, C.L.; Boucher, Y. Vibrio metoecus sp. nov., a close relative of Vibrio cholerae isolated from coastal brackish ponds and clinical specimens. Int J Syst Evol Microbiol 2014, 64, 3208-3214, doi:10.1099/ijs.0.060145-0.

54. Orata, F.D.; Kirchberger, P.C.; Méheust, R.; Barlow, E.J.; Tarr, C.L.; Boucher, Y. The dynamics of genetic interactions between Vibrio metoecus and Vibrio cholerae, two close relatives co-occurring in the environment. Genome Biol Evol 2015, 7, $2941-2954$. Orata, F.D.; Kirchberger, P.C.; Meheust, R.; Barlow, E.J.; Tarr, C.L.; Boucher, Y. The Dynamics of Genetic Interactions between Vibrio metoecus and Vibrio cholerae, Two Close Relatives Co-Occurring in the Environment. Genome Biol Evol 2015, 7, 2941-2954, doi:10.1093/gbe/evv193.

56. Davis, B.R.; Fanning, G.R.; Madden, J.M.; Steigerwalt, A.G.; Bradford, H.B.; Smith, H.L.; Brenner, D.J. Characterization of biochemically atypical Vibrio cholerae strains and designation of a new pathogenic species, Vibrio mimicus. Journal of clinical microbiology 1981, 14, 631-639.

Taniguchi, K.; Nakamura, A.; Tsurubuchi, K.; O'Hara, K.; Sawai, T. Identification of Escherichia coli clinical isolates producing macrolide 2'-phosphotransferase by a highly sensitive detection method. FEMS Microbiol Lett 1998, 167, 191-195, doi:10.1111/j.1574-6968.1998.tb13227.x.

58. McGilvray, D.; Umbarger, H.E. Regulation of transaminase C synthesis in Escherichia coli: conditional leucine auxotrophy. J Bacteriol 1974, 120, 715-723, doi:10.1128/jb.120.2.715-723.1974.

59. Ohman, D.E.; Cryz, S.J.; Iglewski, B.H. Isolation and characterization of Pseudomonas aeruginosa PAO mutant that produces altered elastase. J Bacteriol 1980, 142, 836-842, doi:10.1128/jb.142.3.836-842.1980.

60. Lee, D.G.; Urbach, J.M.; Wu, G.; Liberati, N.T.; Feinbaum, R.L.; Miyata, S.; Diggins, L.T.; He, J.; Saucier, M.; Deziel, E.; et al. Genomic analysis reveals that Pseudomonas aeruginosa virulence is combinatorial. Genome Biol 2006, 7, R90, doi:10.1186/gb2006-7-10-r90. 
61. Takemura, A.F.; Chien, D.M.; Polz, M.F. Associations and dynamics of Vibrionaceae in the environment, from the genus to the population level. Front Microbiol 2014, 5, 38-38, doi:10.3389/fmicb.2014.00038.

62. Colwell, R.R.; Huq, A. Vibrios in the Environment: Viable but Nonculturable Vibrio cholerae. In Vibrio cholerae and Cholera; American Society of Microbiology: 1994; pp. 117-133.

63. Alam, M.; Sultana, M.; Nair, G.B.; Siddique, A.; Hasan, N.A.; Sack, R.B.; Sack, D.A.; Ahmed, K.; Sadique, A.; Watanabe, H. Viable but nonculturable Vibrio cholerae $\mathrm{O} 1$ in biofilms in the aquatic environment and their role in cholera transmission. Proc Natl Acad Sci U S A 2007, 104, 17801-17806.

64. Colwell, R.R.; Brayton, P.; Herrington, D.; Tall, B.; Huq, A.; Levine, M.M. Viable but non-culturable Vibrio cholerae O1 revert to a cultivable state in the human intestine. World J Microbiol Biotechnol 1996, 12, 28-31, doi:10.1007/BF00327795.

65. Faruque, S.M.; Islam, M.J.; Ahmad, Q.S.; Faruque, A.; Sack, D.A.; Nair, G.B.; Mekalanos, J. Self-limiting nature of seasonal cholera epidemics: role of host-mediated amplification of phage. Proceedings of the National Academy of Sciences 2005, 102, 6119-6124.

66. Hussain, N.A.S.; Kirchberger, P.C.; Case, R.J.; Boucher, Y.F. Modular Molecular Weaponry Plays a Key Role in Competition Within an Environmental Vibrio cholerae Population. Front Microbiol 2021, 12, 671092, doi:10.3389/fmicb.2021.671092.

67. Huq, A.; Colwell, R.R.; Rahman, R.; Ali, A.; Chowdhury, M.; Parveen, S.; Sack, D.; Russek-Cohen, E. Detection of Vibrio cholerae $\mathrm{O} 1$ in the aquatic environment by fluorescent-monoclonal antibody and culture methods. Appl Environ Microbiol 1990, 56, 2370-2373.

68. Bustin, S.A.; Benes, V.; Garson, J.A.; Hellemans, J.; Huggett, J.; Kubista, M.; Mueller, R.; Nolan, T.; Pfaffl, M.W.; Shipley, G.L.; et al. The MIQE guidelines: minimum information for publication of quantitative real-time PCR experiments. Clin Chem 2009, 55, 611-622, doi:10.1373/clinchem.2008.112797.

69. Schmid-Hempel, P.; Frank, S.A.J.P.p. Pathogenesis, virulence, and infective dose. J PLoS pathogens 2007,3 , e147.

70. Kothary, M.H.; Babu, U.S. Infective dose of foodborne pathogens in volunteers: a review. Journal of food safety 2001, 21, 4968.

71. Alam, M.; Sultana, M.; Nair, G.B.; Sack, R.B.; Sack, D.A.; Siddique, A.K.; Ali, A.; Huq, A.; Colwell, R.R. Toxigenic Vibrio cholerae in the aquatic environment of Mathbaria, Bangladesh. Appl Environ Microbiol 2006, 72, 2849-2855, doi:10.1128/AEM.72.4.2849-2855.2006.

72. Ahmed, F.; Fakhruddin, A.N.M.; Imam, M.D.T.; Khan, N.; Abdullah, A.T.M.; Khan, T.A.; Rahman, M.M.; Uddin, M.N. Assessment of roadside surface water quality of Savar, Dhaka, Bangladesh using GIS and multivariate statistical techniques. Applied Water Science 2017, 7, 3511-3525, doi:10.1007/s13201-017-0619-0.

73. Nasreen, T.H., N.A.S.; Islam, M.T.; Orata, F.D.; Kirchberger, P.C.; Case, R.J.; Alam, M.; Yanow, S.K.; Boucher, Y.F. Simultaneous Quantification of Vibrio metoecus and Vibrio cholerae with Its O1 Serogroup and Toxigenic Subpopulations in Environmental Reservoirs. Pathogens 2020, 9, 1053.

74. Rashid, M.u.; Rahman, Z.; Burrowes, V.; Perin, J.; Mustafiz, M.; Monira, S.; Saif-Ur-Rahman, K.; Bhuyian, S.I.; Mahmud, M.T.; Sack, R.B. Rapid dipstick detection of Vibrio cholerae in household stored and municipal water in Dhaka, Bangladesh: CHoBI7 trial. Tropical Medicine International Health 2017, 22, 205-209.

75. George, C.M.; Monira, S.; Sack, D.A.; Rashid, M.-u.; Saif-Ur-Rahman, K.; Mahmud, T.; Rahman, Z.; Mustafiz, M.; Bhuyian, S.I.; Winch, P. Randomized controlled trial of hospital-based hygiene and water treatment intervention (CHoBI7) to reduce cholera. Emerging infectious diseases 2016, 22, 233.

76. Aktar, P.; Moonajilin, M.S. Assessment of Water Quality Status of Turag River Due to Industrial Effluent. International Journal of Engineering and Information Systems (IJEAIS) 2017, 1, 105-118.

77. Sakib, S.N.; Reddi, G.; Almagro-Moreno, S. Environmental role of pathogenic traits in Vibrio cholerae. J Bacteriol 2018, 200, e00795-00717, doi:10.1128/JB.00795-17. 
78. Jutla, A.; Whitcombe, E.; Hasan, N.; Haley, B.; Akanda, A.; Huq, A.; Alam, M.; Sack, R.B.; Colwell, R. Environmental factors influencing epidemic cholera. Am J Trop Med Hyg 2013, 89, 597-607, doi:10.4269/ajtmh.12-0721.

79. Vezzulli, L.; Stauder, M.; Grande, C.; Pezzati, E.; Verheye, H.M.; Owens, N.J.; Pruzzo, C. gbpA as a novel qPCR target for the species-specific detection of Vibrio cholerae O1, O139, non-O1/non-O139 in environmental, stool, and historical continuous plankton recorder samples. PLoS One 2015, 10, e0123983, doi:10.1371/journal.pone.0123983.

80. Sultana, M.; Nusrin, S.; Hasan, N.A.; Sadique, A.; Ahmed, K.U.; Islam, A.; Hossain, A.; Longini, I.; Nizam, A.; Huq, A. Biofilms comprise a component of the annual cycle of Vibrio cholerae in the bay of bengal estuary. mBio 2018, 9, e00483-00418.

81. Pia, H.I.; Aktar, M.; Sarkar, S.; Rahman, A.; Rayhan, A.B.M.S.; Islam, M.M.; Hassan, M. Assessment of water quality varies between pre-monsoon and post-monsoon season of the typical contaminated river of bangladesh. A case study of shitalakhya river, Dhaka. 2018, 3.1, 129-141.

82. Staff Correspondent. 6 Rivers around Dhaka: Water turning untreatable? The Daily Star 2016.

83. LatLong.net. Gabtoli, Dhaka, Bangladesh. Available online: https://www.latlong.net/place/gabtoli-dhaka-bangladesh22624.html (accessed on 2019, June 1).

84. Herigstad, B.; Hamilton, M.; Heersink, J. How to optimize the drop plate method for enumerating bacteria. Journal of microbiological methods 2001, 44, 121-129.

85. Pfaffl, M. Quantification strategies in real-time PCR Michael W. Pfaffl. AZ Quantitative PCR 2004, 1, 87-112. 